Para enlazar con este artículo / To link to this article:

http://dx.doi.org/10.14198/fem.2019.34.14

Para citar este artículo / To cite this article:

Samamé, Luciana. «Falacias anti-feministas». En Feminismo/s, 34 (diciembre 2019): 317-338.

DOI: 10.14198/fem.2019.34.14

\title{
FALACIAS ANTI-FEMINISTAS
}

\section{ANTIFEMINIST FALLACIES}

\author{
LUCIANA SAMAMÉ \\ Universidad Yachay Tech, Ciudad del conocimiento Yachay (Ecuador) \\ lucsamame@yahoo.com.ar \\ https://orcid.org/0000-0002-1630-7846
}

\section{Resumen}

El objetivo específico de este trabajo apunta a la identificación y desmantelamiento de ciertos argumentos falaces con que suele atacarse al feminismo. Dichos argumentos circulan en múltiples contextos que incluyen los medios académicos e intelectuales, así como los medios de comunicación masivos. La importancia de esta tarea es doble, ya que contribuiría al cumplimiento de dos objetivos más generales: por un lado, desmontar aquellas críticas extraviadas que, lejos de fortalecer el debate dentro del feminismo, lo oscurecen y dificultan; por el otro, visibilizar la importancia y vigencia del feminismo. La metodología empleada es de corte analítico-filosófico, y consiste básicamente en el análisis lógico de conceptos y argumentos.

Palabras clave: feminismo; justicia; falacias.

\section{Abstract}

The specific objective of this work is to identify and dismantle certain fallacious arguments usually used to attack feminism. These arguments circulate both in academic and intellectual media, as well as in mass media. The importance of this task is twofold, since it would contribute to the fulfillment of two more general objectives: on the one hand, to dismantle those misguided criticisms that, far from strengthening the debate within feminism, obscure and hinder it; on the other, to make visible the importance and present relevance of feminism. The methodology used

Los contenidos de la revista se publican bajo una licencia de Creative Commons Reconocimiento 4.0 Internacional (CC BY 4.0)

Feminismo/s 34, diciembre 2019, pp. 317-338 
is analytical-philosophical, and consists basically of the logical analysis of concepts and arguments.

Keywords: Feminism; Justice; Fallacies.

\section{INTRODUCCIÓN}

Probablemente no sea exagerado afirmar que nunca antes como ahora ha gozado el feminismo de mayor visibilidad. Los estudios de género se afianzan y multiplican en el mundo académico, al tiempo que el movimiento feminista se instala en la escena pública con una contundencia sin precedentes. En el caso de Argentina, el movimiento «ni una menos», que se originó en calidad de protesta contra el alarmante número de víctimas de femicidio que aquejaba al país, pero también a Latinoamérica toda, consiguió canalizar otros reclamos llevándolos al debate público y a la agenda política, tales como la legalización del aborto, la educación sexual integral en escuelas, o el acoso laboral, entre otros. Con todo, y tal vez debido a esta notoriedad misma, el feminismo se ha convertido en blanco de severas críticas, muchas de ellas desacertadas.

En este trabajo quisiera centrarme en el análisis de un conjunto de creencias injustificadas y argumentos erróneos con los que suele atacarse en la actualidad al feminismo. Con esto no pretendo poner a resguardo a este último de toda tentativa de crítica. Por el contrario, el ejercicio de la sana crítica, que apunta a la revisión constante y razonada de nuestras teorías y prácticas, posibilita su fortalecimiento y mejora, en ciertos casos, o bien su reprobación y relevo, en otros. Sin embargo, cuando las críticas se fundan en argumentos falaces, lejos de nutrirse la discusión al calor de ideas y concepciones plurales, la debilitan y oscurecen. De esta suerte, un paso esencial para el robustecimiento del debate feminista contemporáneo consiste en desmontar aquellas críticas erróneas o que denotan un pensamiento sesgado.

La importancia de poner al descubierto tales bases erróneas es doble: por un lado, coadyuvará en el trazado de un perímetro razonable desde el cual establecer un diálogo fructífero; por otro, permitiría ver con mayor nitidez dónde radican el sentido y la actualidad del feminismoํ.

1. Por razones estilísticas, hablaré de «feminismo», pero con ello no quiero implicar su homogeneidad. Considero, en contraste, que existen diversos feminismos. 
En este artículo se seguirá una metodología filosófica de corte analítico, mediante la cual se analizarán argumentos y conceptos desde una perspectiva lógica. Tales argumentos suelen circular en diversos contextos que abarcan tanto medios académicos como medios masivos de comunicación. Para volver más claros los objetivos perseguidos por este trabajo, el recorrido se dividirá en dos partes: en primer lugar, se tratará de precisar en qué consiste el sentido del feminismo, y en qué radica su actualidad e importancia. En la segunda sección -más extensa-, se propondrá el análisis de siete argumentos erróneos que he dado en llamar «falacias anti-feministas», aunque sin pretender agotar con ello ni la totalidad ni la complejidad de la discusión.

\section{EL FEMINISMO COMO CUESTIÓN DE JUSTICIA}

Reivindicar el feminismo es una cuestión de justicia. Por ello, antes de tematizar los diferentes argumentos que suelen oponérsele, es importante detenerse a reflexionar sobre la significación y vigencia de sus planteamientos y reclamos. Huelga decir que el feminismo es un movimiento heterogéneo, el cual, en calidad de empresa teórica y a un tiempo movimiento social, está atravesado por matices y tensiones. Pese a ello, parece existir un propósito fundamental que anida en sus múltiples manifestaciones: visibilizar, señalar, denunciar actos de injusticia. ¿Y en qué se cifran dichas injusticias? En haberles negado a mujeres de todas las latitudes y de todos los tiempos derechos fundamentales, oportunidades, posibilidades. Tales injusticias se cifran igualmente en la subestimación de aquellas cualidades y rasgos ligados con lo femenino.

Con todo, las clásicas teorías de la justicia se han caracterizado por hacer caso omiso de tales inequidades. La distinción tajante entre la esfera pública y la privada, y el consiguiente confinamiento de las mujeres a la última de ellas -distinción sostenida, característica mas no exclusivamente, por Aristóteles-, marginaba al género femenino de todo asunto de justicia, cuyo manejo sólo podía estar reservado a los ciudadanos de la polis. Varios siglos más tarde, la representatividad de las mujeres en las teorías de justicia no corrió mejor suerte. Si tomamos, en este caso, al moderno contractualismo, los pactantes 
resultan ser siempre varones adultos, cabezas de familia y propietarios ${ }^{2}$. Inclusive la recreación contemporánea del contractualismo en la teoría de la justicia de John Rawls parece adolecer del mismo defecto, aunque de manera más sutil. En opinión de Susan Moller Oskin (9), el filósofo norteamericano asume sin más que la familia es una institución justa, pasando por alto que el desigual reparto de labores en la esfera doméstica suele estructurarse según el género ${ }^{3}$. Esto le lleva a sostener a la autora que no hay posibilidades de erigir sociedades justas en la medida en que un desigual reparto de labores siga dominando la esfera doméstica (14).

La sostenida invisibilización de las mujeres en diferentes teorías de la justicia resulta sin más inexcusable. Su ausencia resulta inexcusable no solamente por haber sido víctimas de injusticias sistemáticas, sino además por haber sido excluidas de la esfera política y, por ende, de la posibilidad de establecer ellas mismas los principios básicos de justicia que han de regular la sociedad. Si bien se han dado formidables pasos en este sentido, la lucha del feminismo no está acabada, justamente porque existen múltiples puntos del planeta donde innumerables mujeres continúan siendo víctimas de marcadas inequidades, las cuales se hacen más profundas al combinarse con la pobreza. Tal como sostiene Martha Nussbaum en Women and Human Development (4), tanto el pensamiento económico como político internacional deberían ser en esencia feministas, atentos a los problemas especiales que las mujeres enfrentan a causa de su sexo en prácticamente cada nación del mundo; pues sin un adecuado entendimiento de tales problemas, asuntos generales de pobreza y desarrollo no pueden ser bien encarados.

Es mérito de la teoría política feminista contemporánea haber puesto al descubierto las «injusticias» que las teorías de la justicia tradicionales, paradójicamente, ocultaban. Típicamente, la desigual distribución en las

2. O como sostiene Martha Nussbaum (Frontiers 14): los contractualistas clásicos asumían que los agentes que negociaban y pactaban entre sí, eran iguales en capacidades, como asimismo también, capaces de actividad económica productiva. En tales condiciones originales de negociación, se omitían precisamente aquellas personas «improductivas»: mujeres, niñas y niños, personas de tercera edad.

3. Para un análisis de las limitaciones de la teoría de la justicia rawlsiana en el marco de la filosofía política feminista, véase el texto de M. Victoria Costa «The Indeterminacy of Rawls's Principles of Justice for Women's Freedom from Domination».

Feminismo/s 34, diciembre 2019, pp. 317-338 
tareas de cuidado y crianza, con su consiguiente impacto en el desigual desarrollo profesional de las mujeres y en el acceso a la vida pública (Moller Oskin 170-2). Otra noción importante que el feminismo contemporáneo se ha encargado de visibilizar concierne al papel de medio, antes que de fin, concedido históricamente a las mujeres -reproductoras, cuidadoras, objetos sexuales- (Nussbaum, Frontiers 70-71). Semejantes tipos de injusticia han estado vinculados entonces a diferentes factores, si bien concatenados entre sí: desigual distribución del trabajo doméstico, desigual acceso a oportunidades -de desarrollo profesional, de acceso a cargos públicos o jerárquicos-, desigual valoración de las capacidades. Con relación a esto último, y tal como se ha dicho más arriba, otra de las formas típicas en que se ha cometido injusticia en contra de las mujeres ha sido a partir de la desvalorización de aquellos aspectos ligados con lo femenino: la emocionalidad, la vulnerabilidad, la dependencia.

No es casual, a este respecto, que las clásicas teorías de la justicia se hayan mostrado reticentes ante la incorporación de las emociones entre sus conceptos básicos. Durante mucho tiempo, se ha tendido a ver en la emocionalidad una amenaza a la imparcialidad y la racionalidad, aspectos inseparables de la justicia. Sin embargo, no son pocos quienes reconocen actualmente que la actitud imparcial, esencial para la justicia, no consiste en una actitud fría y distante, sino por el contrario, en una actitud emocional fuertemente asociada con la empatía (Deigh 73-90, Roberts 14-28, Salles 217-226, Solomon 20-42). Un importante puntapié en este sentido fue dado por Carol Gilligan, quien en su influyente libro In a different voice: Psychological theory and women's development, se propuso reivindicar cualidades morales «femeninas» ${ }^{4}$ como la atención y el sentir con otros, el juicio moral matizado y sensible a las particularidades del caso concreto. La tesis de Gilligan es que la moralidad de los principios abstractos y racionales es una moralidad masculina contrastante con una moralidad del cuidado, basada en la emocionalidad y las relaciones

4. La idea de que existen cualidades propiamente femeninas es una idea controvertida. La misma ha sido duramente criticada por otra vertiente del feminismo, precisamente por ver en ello una estrategia de dominación por parte del patriarcado: lo femenino no sería más que un constructo social empleado en detrimento de las mujeres.

Feminismo/s 34, diciembre 2019, pp. 317-338 
afectivas, la cual resultaría, a la postre, mayormente adecuada para fundar la moralidad (Rachels 245-63).

Es así que la reivindicación de nociones tales como las de emocionalidad o interdependencia ha venido a enriquecer nuestras teorías morales y políticas. Particularmente relevante ha resultado la tentativa, por parte de autoras feministas, de incorporar centralmente dichas nociones a la hora de bosquejar una teoría de la justicia. Con todo, establecer el modo en que una teoría de la justicia feminista habría de ser erigida, sobrepasa con creces el objetivo de este apartado. El propósito, en contraste, es mucho más modesto: insinuar la conexión intrínseca entre feminismo y justicia, y la dirección que una teoría de la justicia podría adoptar a partir de las valiosas aportaciones de las autoras mencionadas. Asimismo, un abordaje sumamente fértil de la cuestión es avanzado por Judith Shklar en The faces of injustice: en su opinión, en lugar del concepto de «justicia», sería mejor partir, desde un punto de vista metodológico y heurístico, del concepto de «injusticia». Dicha noción, en cierta manera, nos resulta más comprensible -a pesar de toda su complejidad-que la de justicia ${ }^{5}$. Prueba de ello es que solemos señalar con mayor frecuencia «esto es injusto» que «esto es justo» (Shklar 16).

Siguiendo la pista de Shklar, y tomando entonces como noción primaria aquella de injusticia antes que de justicia, parece palpable el sentido en que mujeres de todo tiempo y lugar han sido víctimas de injusticia: ya sea por negárseles derechos fundamentales, tales como el de participar en la vida pública, el derecho a la libertad de expresión, de movimiento, de asociación; ya sea por perjudicarlas activamente -mediante el insulto, la difamación, y en casos extremos, aunque lamentablemente nada infrecuentes, mediante el maltrato, la tortura y la muerte-, por el mero hecho de ser mujeres. Negar

5. El argumento de Shklar podría ser complementario del siguiente razonamiento, ya avanzado por Schopenhauer (236-250) en el siglo XIX: somos capaces de comprender lo que es la justicia porque tenemos primero una noción de injusticia. Esta es entonces el hecho primario, aquello que somos capaces de percibir por derecho propio, en forma clara y distinta. Esto significa que cuando algo injusto ocurre, lo percibimos de inmediato. Ello suele venir acompañado de emociones tales como la indignación o la ira, hasta tal punto que, si fuéramos incapaces de indignarnos, seríamos incapaces de percibir una injusticia. En conclusión: necesitamos establecer primero en qué consiste esta última, antes de esbozar un concepto de justicia. La injusticia es algo que se sufre y se padece, y por ello, es incapaz de pasarnos desapercibida.

Feminismo/s 34, diciembre 2019, pp. 317-338 
derechos y oportunidades, y más aún, lesionar directamente a una mujer por la simple razón de ser mujer, son actos a todas luces injustos. Semejantes actos podrían estar correlacionados con creencias erróneas y argumentos falaces ${ }^{6}$. De allí la importancia de señalarlos y desmontarlos, tal como se intentará hacer en lo que sigue.

\section{FALACIAS ANTI-FEMINISTAS}

\section{1. «Las feministas son feminazis»}

Antes de emprender nuestro análisis, tal vez sea necesario recordar en qué consiste una falacia: esta consiste, básicamente, en un razonamiento defectuoso que suele cometerse de forma típica. Según Copi y Cohen (125), un razonamiento puede ser erróneo por dos razones: o bien porque se asume entre sus premisas una proposición falsa, o bien porque no logra establecerse lógicamente la conclusión a partir de las premisas dadas. Adicionalmente, las falacias se caracterizan por revestir la apariencia de un razonamiento correcto que, con todo, no lo es. Por ello acostumbra a decirse que, a pesar de su invalidez lógica, resultan «psicológicamente persuasivas». En ocasiones, un razonamiento falaz puede ser sutil y difícilmente detectable, pero en otras, puede percibirse fácilmente debido a su evidente tosquedad. El primer caso que se analizará pertenece a este último tipo, pues su error es tan grosero que salta inmediatamente a la vista.

Existe una suerte de leitmotiv extendido en nuestros días, a través del cual las feministas son tildadas de «feminazis». La comparación del feminismo con el nazismo es sin duda malintencionada, ya que su único propósito parece apuntar a la mera descalificación sin ofrecerse ninguna razón ulterior. El tipo

6. Con esto no se pretende sostener que existe una causalidad directa entre formas falaces de razonar acerca del feminismo y la violencia machista, por ejemplo. Desde un punto de vista epistemológico, es sumamente difícil establecer causalidades en el mundo social (aunque el mundo natural tampoco está exento de esta dificultad). En función de ello, resulta más apropiado hablar de «correlaciones». Sin duda, el machismo es una ideología que comporta un ejercicio de poder complejo. Es tarea de la sociología empírica y la psicología, entre otras disciplinas, establecer el modo en que efectivamente opera. En este trabajo se asume una hipótesis más modesta: que ciertas maneras erróneas de razonar sobre el feminismo obstaculizan su aspiración fundamental: visibilizar distintos tipos de injusticias que sufren las mujeres con el objeto de erradicarlas.

Feminismo/s 34, diciembre 2019, pp. 317-338 
de argumentación aquí implicada podría tipificarse como una falacia ad-hominen (o mejor, ad-feminam) en su versión abusiva. Podría reconstruirse de la siguiente manera:

- El nazismo es una ideología totalitarista y, por tanto, reprobable.

- El feminismo es una ideología totalitarista.

- Las feministas son feminazis.

Se incurre en esta clase de falacia cuando, en lugar de discutirse una idea, tesis o concepción, se ataca a la persona que la defiende o sustenta, normalmente mediante la atribución de ideologías o cualidades morales reprobables. La equiparación del feminismo con el nazismo no es más que una maniobra argumental que omite someter a discusión racional tesis alguna. En lugar de ello, se desvía el foco de atención hacia una ideología deleznable que, en este caso, presuntamente subyacería al feminismo. En consecuencia, falacias de este tipo constituyen falacias de relevancia.

Asimismo, aquellos razonamientos en los que se induce una asociación con Hitler o el nazismo suelen ser directamente considerados como malos argumentos. Todavía más: Frank Scalambrino denomina a semejante maniobra argumental reductio ad Hitlerum (212-214). En su opinión, se trata de una especie de falacia que se deriva del género ad-hominem. Toda vez que en un argumento se introduce una comparación con Hitler o el nazismo, habría buenas razones para desecharlo en calidad de mal argumento, o bien considerar que quien lo introduce, ha errado el punto. Esta podría considerarse una regla general que nos permitiría desmantelar semejante forma de razonar. En conclusión, la falacia que aquí estamos analizando, envuelve un error tan burdo que puede ser desarticulada sin mayor dificultad. Pasemos entonces al análisis de la siguiente.

\section{2. «Ni machismo ni feminismo»}

Este argumento suele ser aducido por quienes se jactan de ostentar una posición neutral. En su opinión, ser feminista -o machista-implicaría tomar partido por una de las partes en detrimento de la otra. Y como esto supondría una lesión al principio de igualdad, entonces lo correcto sería la neutralidad (ni machista ni feminista). Con bastante frecuencia escuchamos este argumento 
que, prima facie, podría resultar convincente; sin embargo, hay algo errado en él. En una de sus reconstrucciones posibles, parece razonarse de este modo:

- Hombres y mujeres son iguales desde un punto de vista jurídico.

- Ser machista implicaría estar en favor de los hombres y en detrimento de las mujeres.

- Ser feminista implicaría estar en favor de las mujeres y en detrimento de los hombres.

- Por lo tanto, la defensa de la igualdad exige no comprometerse ni con el machismo ni con el feminismo.

En este razonamiento, podría cuestionarse la verdad de la tercera premisa: el reclamo feminista simplemente apunta a la corrección de aquellas injusticias característicamente cometidas en contra de mujeres y nada tiene que ver, entonces, con un reclamo que perjudicaría a los hombres. Es decir que, en su lugar, debería incluirse una premisa donde se consigne que ha existido y todavía existe un desbalance entre hombres y mujeres en lo que a igualdad de derechos y oportunidades respecta. Luego ser feminista no implicaría inclinar el asunto en favor de una parte -las mujeres- en perjuicio de la otra -los hombres-, sino simplemente en equilibrar la balanza, precisamente por un desequilibrio previamente dado entre ambos.

Existe adicionalmente otro fallo en el argumento que estamos analizando y que consiste en poner en pie de igualdad dos conceptos incomparables -«machismo» $\mathrm{y}$ «feminismo»-, dada su desigual orientación respecto a valores como la justicia y la equidad. Mientras el concepto de feminismo posee una carga normativa aceptable, consistente en reivindicar para las mujeres igualdad de derechos y oportunidades, el concepto de machismo posee una carga valorativa inaceptable, o cuanto menos criticable, al presuponer la superioridad del varón sobre la mujer. Mientras el feminismo conlleva una lucha por la erradicación de la injusticia, el machismo es generador de múltiples formas de injusticia. Estas diferencias sustantivas vuelven incomparables ambos conceptos. La falacia que se comete al decir «no soy feminista ni machista», pretendiendo defender con ello una posición igualitarista, tal vez pueda verse más claramente si se la compara con esta otra: «no estoy a favor ni del opresor ni del oprimido». 


\section{3. «La naturaleza hace diferentes a hombres y mujeres. La biología, por tanto, condiciona nuestros roles y funciones sociales.»}

En este caso, nos enfrentamos a un argumento más elaborado y lo suficientemente extendido como para merecer un análisis mayormente detallado. La apelación a diferencias naturales entre hombres y mujeres es, en efecto, el recurso más difundido y culturalmente arraigado para justificar sus diferentes roles sociales. En la historia de la ciencia y de la filosofía abundan ejemplos de este tipo. En su Política (1259 b), Aristóteles sostenía que la relación entre el varón -el cabeza de familia- y la mujer era comparable a la existente entre gobernante-gobernado, y que esta relación desigual se fundaba en una desigualdad natural entre ambos. Sin embargo, no necesitamos retrotraernos a la Antigüedad para constatar una concepción de este tipo. Hasta bien entrado el siglo XIX, se esgrimieron ideas similares, sustentadas tanto por el discurso filosófico como por el científico, en especial, las ciencias médicas. Desde esta singular óptica, se acostumbraba a alegar que los roles desparejos que hombres y mujeres ocupan en la sociedad, se desprendían de condicionamientos biológicos que, aunque quisiéramos, no podríamos evitar. Así, por ejemplo, se han invocado diferencias anatómicas, fisiológicas, hormonales, cromosómicas, que explicarían en última instancia las diferencias entre los sexos (Pujal 18).

Con base en estas desemejanzas naturales, se concluía que los hombres eran más aptos para ciertas tareas -normalmente los cargos asociados al mando o al gobierno, y las tareas asociadas con el pensamiento abstracto (la ciencia) - mientras que las mujeres, para otras -usualmente las que tienen que ver con la crianza y el cuidado- ${ }^{7}$. Dichas disimilitudes se han naturalizado tanto a lo largo del tiempo que no es inusual, todavía hoy, continuar aduciendo que los roles diferentes que hombres y mujeres ocupan en la sociedad se fundan en las mencionadas diferencias naturales. Paradójicamente,

7. Siguiendo esta lógica, a los hombres se les ha considerado tradicionalmente más aptos para el pensamiento abstracto y la ciencia, mientras que a las mujeres, para cuestiones más concretas como las manualidades. A los hombres, más aptos para la vida pública (cargos y funciones políticas), mientras que a las mujeres para la vida privada (la esfera doméstica). A los hombres, más aptos para el trabajo (proveedor), a las mujeres, para el cuidado (madre). A los hombres, para ciertas profesiones (juez, médico, empresario); a las mujeres, para otras (secretaria, enfermera). Y la lista podría continuar.

Feminismo/s 34, diciembre 2019, pp. 317-338 
este discurso ha encontrado en la actualidad un aliado fundamental en las neurociencias - una perspectiva que suele considerarse a la vanguardia en ciencias sociales-. Quizás un caso que merezca ser mencionado sea el del denominado «feminismo científico», punto de vista liderado, en el caso de Argentina, por Roxana Kreimer.

La bandera del «feminismo científico» ${ }^{8}$ está dada, en efecto, por las neurociencias y las ciencias cognitivas, en especial, la psicología evolucionista. En su opinión, es necesario partir de los datos duros que nos proporcionan las ciencias empíricas para teorizar acerca de ámbitos sociales y humanos. Así, su blanco de ataque está dado por lo que denominan el «feminismo hegemónico», al cual se le adscribe un constructivismo social recalcitrante ${ }^{9}$. La tesis que el feminismo científico defiende es que las diferencias entre hombres y mujeres no pueden explicarse en función de una educación y sociedad patriarcales -cosa que niegan-, sino más bien en función de mecanismos adaptativos divergentes inscritos en nuestro pasado evolutivo. Subsidiariamente, el feminismo científico le endilga al feminismo hegemónico un diagnóstico social erróneo por hacer caso omiso de tales diferencias, y con base en ello, se deslegitiman algunos de sus clásicos reclamos -como por ejemplo, aquellos relacionados con la violencia de género ${ }^{10}$ o la brecha salarial-.

En resumidas cuentas, el feminismo científico le atribuye a la biología una autoridad explicativa incuestionable respecto de la conducta humana. Esto

8. El feminismo científico es todavía una tentativa incipiente que no cuenta con demasiada producción teórica ni académica propias. A este respecto puede consultarse su página web: https://feminismocientific.wixsite.com/misitio/nosotros

9. Las constructivistas consideran que no existe algo así como una naturaleza o realidad en estado puro: los conceptos, aparatos teóricos y metodológicos con los que abordamos el estudio de la naturaleza son constructos humanos. Desde esta perspectiva, podría decirse que el posicionamiento que apela a las diferencias naturales entre hombres y mujeres para justificar los diferentes roles que deberían ocupar, apela en el fondo a una realidad construida: la «naturaleza» no es una cosa que esté dada y que exista con independencia de nosotras, se trata más bien de un concepto creado por los seres humanos y, por tanto, de un producto cultural entre otros. En esta línea se ha argumentado que incluso la categoría de «sexo», antes que natural y biológica (como normalmente se la considera), es un constructo teórico (Butler 70-85). En esta misma línea argumentan también Maffía y Cabral (86-96).

10. Para el feminismo científico, existe la violencia sin más, de manera que se niega el concepto de «violencia de género».

Feminismo/s 34, diciembre 2019, pp. 317-338 
no significa negar que la cultura sea también un factor explicativo, sino más bien conceder que en nuestras teorizaciones sociales no podemos prescindir de las ciencias empíricas. En otros términos, el feminismo científico aboga por una suerte de naturalización de las teorías feministas y de los estudios de género. Con respecto a este posicionamiento, cabe decir lo siguiente: si bien tal pretensión es atendible y cuenta con puntos en su favor, no por ello está exenta de dificultades a las que debería dar respuesta. En primer lugar, la creencia según la cual existiría una especie de demarcación nítida entre lo natural y lo cultural. Con respecto a esto último, es sabido que el concepto de «naturaleza» es un concepto vago ${ }^{11}$. En segundo lugar, y aun asumiendo que existieran elementos naturales en estado puro, capaces de entablar interacciones con aspectos culturales, el feminismo científico debería ser capaz de explicar el modo en que ambos aspectos interactúan (esto es, qué tipo de causalidad o influjo tendría el mundo natural sobre el mundo social).

Pese a estas dificultades, podría todavía concederse que aspectos naturales y biológicos desempeñan un rol explicativo significativo en las teorías sociales y humanas. Sin embargo, un punto álgido es si pueden desempeñar un papel justificativo, ya que buena cantidad de las ciencias sociales o humanidades, a la par de su dimensión descriptiva, posee una dimensión normativa. Es usual que un sociólogo o un cientista político no se interesen exclusivamente por el funcionamiento efectivo de las instituciones u organizaciones, sino también por el modo en que deberían funcionar; esto es, proponer en qué consistiría un diseño institucional adecuado y deseable. De similar manera, a la teoría feminista no le interesa solamente explicar los factores mediante los cuales se llegaron a instalar diferencias sustantivas entre hombres y mujeres. El feminismo posee, igualmente, un fuerte componente normativo/valorativo, y por ello su reclamo fundamental apunta a la erradicación de prácticas injustas, es decir, a establecer pautas normativas que regulen el mundo social.

Al llegar a este punto, la pregunta que debemos formular es la siguiente: ¿pueden las ciencias empíricas, a la par que ofrecer una explicación de

11. En palabras de Oseguera Gamba (46-47): «Es claro que algunas cosas son naturales, como la necesidad de alimentarse, pero ¿es el usar ropa algo natural? ¿Es la utilización del fuego por parte del ser humano algo natural? ¿Qué hay de nuestra tendencia a explotar el medio ambiente?»

Feminismo/s 34, diciembre 2019, pp. 317-338 
dimensiones sociales y humanas, servir de base para justificarlas? Este problema es del todo complejo y su enunciación y tratamiento explícitos pertenecen fundamentalmente al ámbito de la filosofía moral y la lógica. Fue David Hume el primero en advertir que del modo en que son las cosas, no se sigue (lógicamente) cómo deberían ser. Dicho de otro modo: no se puede inferir enunciados prescriptivos de enunciados descriptivos como los científicos. Suele asociarse este paso injustificado del ser al deber ser con la «falacia naturalista»-así denominada por G. Moore ${ }^{12}$.

Un análisis pormenorizado de la misma, dada su complejidad y la multiplicidad de aristas que envuelve, sobrepasa los propósitos de este trabajo. Con todo, y siguiendo el hilo argumentativo proseguido hasta aquí, se asumirá que el pasaje de enunciados descriptivos a enunciados normativos no se da de suyo y que, por tanto, se trata de una maniobra argumental falaz, o cuanto menos, muy problemática. Lo mismo cabe decir respecto de la diferenciación entre explicación y justificación: confundir ambas dimensiones conduce normalmente a razonamientos erróneos ${ }^{13}$.

Teniendo en cuenta lo precedente, podría estipularse lo siguiente: en el ámbito que nos ocupa, es innegable que se han utilizado argumentos de tal tipo para justificar diferencias sociales entre hombres y mujeres, a partir de la derivación -injustificada- de enunciados normativos (v.g.: «las mujeres

12. Si bien Moore acuñó esta expresión en sus Principia Ethica (1903) para referirse a la imposibilidad (lógica) de definir «bueno» en relación con propiedades naturales, la expresión ha llegado a emplearse para cubrir un amplio espectro de razonamientos falaces, o cuanto menos problemáticos: a) la derivación de proposiciones prescriptivas de enunciados descriptivos; b) tomar explicaciones como justificaciones; c) asumir que las cosas son como deben ser; d) asumir que todo lo natural es bueno; e) presuponer que lo que va en dirección de la evolución es mejor (Oseguera Gamba 8). Si bien cada una de estas variantes merecería un tratamiento particularizado, aquí no haremos mayores distingos por razones metodológicas. A los efectos del presente trabajo, es relevante señalar lo siguiente: las diferentes acepciones de «falacia naturalista» presentan un parecido de familia, consistente, entre otras cosas, en ser funcionales al mantenimiento del statu quo.

13. Por ejemplo, aquello que podría servir para explicar una conducta no serviría para justificarla, como en el siguiente caso: un sujeto $x$ mata a un sujeto $y$, motivado por celos y ambición. Estas emociones servirían indudablemente para comprender y explicar dicha conducta, pero en modo alguno para justificarla (sobre todo desde un punto de vista moral).

Feminismo/s 34, diciembre 2019, pp. 317-338 
deberían dedicarse al cuidado de los hijos y del hogar») de enunciados descriptivos (v.g: «las mujeres poseen un instinto maternal natural ${ }^{14}$ ). Apelando a sus desemejanzas naturales, se ha legitimado todo tipo de injusticias en detrimento de estas últimas (precisamente por haber sido las cualidades naturales ligadas a la «masculinidad» mayormente apreciadas). Así, por ejemplo, se ha llegado a decir que, dado el tamaño de su cerebro, las mujeres no serían aptas para la ciencia y la filosofía, y en consecuencia, no debían aspirar más que a las labores domésticas. Diana Maffia (67) reconstruye este tipo de razonamiento en el que se apela falazmente a la naturaleza, de la siguiente manera:

- Se señalan diferencias biológicas y psicológicas naturales e inevitables entre hombres y mujeres.

- Se jerarquizan esas diferencias de modo tal que las características femeninas son siempre e ineludiblemente inferiores a las masculinas

- Como consecuencia, se justifica el status social de las mujeres en tal inferioridad biológica.

Tal como se ha indicado, semejante forma defectuosa de razonar ha sido moneda corriente a lo largo de cuantiosos siglos. En la actualidad, es más difícil encontrarla formulada de ese modo tan tosco; sin embargo, continúa presentándose de maneras más sutiles. Este sería el caso, precisamente, del feminismo científico: por un lado, aparece a la vanguardia de ciertas teorías en boga (especialmente vinculadas con las neurociencias), pero por el otro, es inevitable asociarlo con las perspectivas más conservadoras en materia de género, por su apelación constante a la biología. De esto se desprende que su alcance es limitado, dado que el papel preponderante que el feminismo científico concede a las ciencias empíricas podría, en el mejor de los casos, gozar de un poder explicativo, mas no justificativo. Tan pronto se da este paso, se tropieza con intrincadas dificultades lógicas asociadas con la falacia naturalista, falacia que, por lo demás, puede envolver serias consecuencias prácticas, como su contribución al mantenimiento del statu quo (Nelson 360).

Si el análisis ofrecido hasta aquí es correcto, resulta de la máxima importancia visibilizar y desmantelar esta falacia, puesto que la apelación a la

14. Aun suponiendo que el enunciado descriptivo fuera verdadero, no sería legítimo desprender del mismo un enunciado prescriptivo. 
naturaleza y a la biología no ha perdido nada de su fuerza: sigue siendo un lugar común y un poderoso instrumento para instaurar diferencias entre hombres y mujeres, diferencias que, insistimos una vez más, podrían jugar un rol explicativo en las ciencias sociales, mas de ninguna manera un rol valorativo/normativo.

\section{4. «El lenguaje inclusivo es una aberración o deformación de la lengua»}

No solamente los roles sociales y los puestos de trabajo han estado históricamente colonizados por la ideología de género. También el lenguaje ${ }^{15}$. El hecho de que, por ejemplo, se use la expresión «el hombre» para referirse a hombres y mujeres, o que en el uso del plural se privilegie el artículo masculino «los», son apenas algunas muestras de cómo la creencia de que sólo el varón puede ser considerado en calidad de auténtico sujeto y representante de toda la humanidad, se ha colado en el lenguaje ${ }^{16}$. Se trata de una injusticia lingüística que, como toda injusticia, debe ser reparada. Y en este caso, la reparación debe ser realizada a través de la modificación de estos usos del lenguaje, propiciando la desaparición de algunos de ellos y la introducción

15. Para un estudio de las relaciones entre lenguaje y sexo, véase Violi (120). En este texto la autora plantea que el androcentrismo permea espacios materiales y simbólicos, como es el caso de la lengua. En tal sentido, la diferencia sexual estaría inscrita en la lengua y generaría, por su parte, «efectos de realidad». Al comentar esta posición, Franulic Depix (16) dice lo siguiente: «si la carencia está en el lenguaje mismo, empobrecido en sus significaciones, marcado estructuralmente por el androcentrismo, inscrita en él la diferencia sexual que representa lo femenino como negación y como condición de existencia del masculino, no debe sorprender que las prácticas sexistas se mantengan, aun cuando las mujeres hayan conseguido una cierta igualdad de oportunidades». Comparto en esta dirección la idea de que los usos lingüísticos no son solamente neutrales o asépticos, sino también factores intervinientes en las prácticas y relaciones humanas, de tal manera que son capaces de orientarlas en un sentido antes que en otro. Nuestras prácticas lingüísticas reflejan modos de ver y valorar la realidad que han sido profundamente modelados por el androcentrismo. De allí la necesidad de modificar estas prácticas lingüísticas, tesis que se pretende defender en este apartado.

16. Aunque por supuesto esta tesitura es negada por ciertos sectores: en este sentido, el director de la RAE ha declarado recientemente que no debe confundirse la gramática con el machismo, desestimando de este modo la idea de que la lengua sea permeable a, o pueda reflejar, la estructura patriarcal que la sociedad ha encarnado durante siglos.

Feminismo/s 34, diciembre 2019, pp. 317-338 
de otros nuevos. Con todo, no es poca la resistencia que suele presentarse ante dicha tentativa. Si bien es cierto que algunos de los argumentos empleados para oponerse al lenguaje inclusivo son atendibles, aquí interesa señalar aquellos que, al parecer, son desacertados y que, en consecuencia, deberían ser desestimados en la discusión sobre el tema.

En esta dirección, es posible identificar al menos dos argumentos que circulan frecuentemente en medios intelectuales y académicos. El primero de ellos podría calificarse, a los presentes propósitos, de «escéptico»: aquel que aduce que los cambios que eventualmente se introduzcan a través del lenguaje inclusivo serán en el mejor de los casos, superfluos e insustanciales, dado que los «verdaderos cambios» deberían operarse en esferas más elementales de la vida humana ${ }^{17}$. Quienes alegan semejantes razones parecen apuntar, en suma, que cuestiones relativas a la modificación de nuestros hábitos lingüísticos serían apenas secundarias respecto de otras cuestiones más urgentes e importantes.

Frente a este posicionamiento, cabe replicar lo siguiente: ¿acaso no conforma el lenguaje una dimensión esencial y constitutiva de la condición humana? La visión instrumental del lenguaje, concebido como simple medio de comunicación, o como herramienta subsidiaria del pensamiento, ha sido superada tras el giro lingüístico que muchas disciplinas sociales y humanas acometieron en el siglo XX. De manera que la opinión conforme a la cual los usos lingüísticos atañen a cuestiones secundarias antes que cruciales, entraña una concepción del lenguaje altamente cuestionable y que goza en la actualidad de muy poca adhesión. De todos modos, y aun aplicando el principio de caridad a la posición rival, concediendo que existen, en efecto, esferas más sustanciales que el lenguaje, de ello no se sigue que el lenguaje no deba ser modificado. Una cosa no implica la otra.

En segundo lugar, existe otro argumento que podría calificarse de «conservador»: el que se opone a la modificación de la lengua apelando a una presunta perfección o asepsia que le es propia. Según esta perspectiva, la

17. Esta es, por ejemplo, la opinión de la lingüista Concepción Company; opinión recogida en la siguiente nota periodística: https://www.eleconomista.com.mx/arteseideas/ El-lenguaje-inclusivo-distrae-del-verdadero-problema-de-fondo-ConcepcionCompany-20190825-0085.html

Feminismo/s 34, diciembre 2019, pp. 317-338 
lengua configuraría algo así como un dominio independiente e inmune a influencias «externas», tales como creencias o prácticas sociales ${ }^{18}$. Sobre la base de tal concepción, se afirma que la lengua está bien como está, y que por eso, no debería ser modificada. Pues bien, frente a este posicionamiento conservador, que se aferra a una condición existente, cabe señalar dos cosas: a) la lengua no está bien como está, y por eso es deseable su modificación en vistas de un lenguaje inclusivo (se trata de un acto de justicia y de reparación, y por tanto, de un imperativo ético); b) la lengua es todo lo contrario de una estructura estática: se trata, por el contrario, de una complejísima estructura en permanente dinamismo y movimiento. Quienes apelan por tanto al argumento conservador según el cual la lengua no debería modificarse, parecen presuponer en su razonamiento una creencia errónea. Su perspectiva, en consecuencia, puede ser desafiada.

\section{5. «El feminismo terminará por volverse en contra de las mujeres»}

Aunque este razonamiento lo escuchemos con suma frecuencia, no está muy claro lo que quiere decir ni cuál es la secuencia lógica subyacente. En primer lugar, porque se refiere a un estado de cosas futuro que, en general, es difícil de anticipar y mucho menos, de predecir. ¿Qué es entonces lo que se quiere decir? ¿Que las mujeres perderán privilegios y que se terminarán perjudicando? Si es así, semejante idea no resiste el menor análisis, puesto que apenas con un poco de conciencia histórica y de conocimiento empírico, es dable constatar que mujeres de todo el mundo y de todos los tiempos han estado al margen de ciertos «privilegios» (el «privilegio» de participar activamente en política, el «privilegio» de estudiar o de trabajar, el «privilegio» de tomar decisiones en forma autónoma). ¿Qué es, entonces, lo que se quiere decir?

Aquello que parece yacer detrás de este decir poco diáfano es una amenaza, comparable a la que Yahveh lanza en el Antiguo Testamento a Adán y Eva si osan probar el fruto del conocimiento. ¿En qué consiste el acto de amenazar? Básicamente, en advertir que si se comete una acción $x$, sobrevendrá un castigo $y$. Luego, quienes afirman «el feminismo terminará por volverse en contra de las mujeres» estarían lanzando una amenaza velada: «si osan

18. Esta tesis es, una vez más, desafiada por Violi, para quien existen profundas relaciones entre la estructura de la lengua y la estructura social.

Feminismo/s 34, diciembre 2019, pp. 317-338 
conquistar derechos y ocupar lugares que antes les estaban vedados, serán castigadas por dicha transgresión». Como puede entreverse, este argumento incurre en la denominada falacia de apelación a la fuerza (Ad-baculum), donde se intenta establecer una conclusión, no sobre la base de buenas razones, sino sobre la base del amedrentamiento (Comesaña 80-82).

Las emociones suelen configurar importantes resortes de la acción. Por ello, la tentativa de insuflar temor en función de eventuales consecuencias futuras puede resultar a fin de cuentas un incentivo para la acción, o bien para su inhibición. Por supuesto que no siempre resulta falaz apelar a la emoción en diferentes contextos argumentativos. De allí la importancia de analizar si dicha apelación es relevante respecto de la conclusión que desea establecerse. El razonamiento, al decir de Wrisley (99), es falaz si presenta la siguiente estructura:

- Se dan razones $\mathrm{x}, \mathrm{y}, \mathrm{z}$, una o más de las cuales apuntan a infundir temor en caso de que cierta acción, $\mathrm{C}$, suceda o bien no suceda.

- Se concluye que C debería suceder, o no.

En el caso que nos ocupa, resulta palmaria semejante estructuración del razonamiento, al implicarse la siguiente serie de proposiciones: «si la revolución feminista no se detiene, las mujeres terminarán sufriendo daños inevitables» (aunque no se especifica en qué consistirían tales daños). Al intentar establecer semejante conclusión sobre la base del temor, sin ofrecerse razones adicionales, este argumento evidencia una debilidad lógica incontestable, por lo que habría de ser sin más desechado.

\section{6. «El feminismo es desmesurado»}

No es inusual por estos días, frente al enorme activismo feminista en la vía pública, escuchar cosas tales como: «a las mujeres se les va la mano», «sus expresiones y manifestaciones son desproporcionadas, impúdicas, exageradas». Opiniones de este tipo no parecen estar sustentadas, en el fondo, en razones, sino más bien en prejuicios y en un conservadurismo recalcitrante. En primer lugar, resulta irrisoria esta acusación de «desproporción». ¿Desproporción respecto a qué? ¿De qué se trata aquello en virtud de lo cual se está protestando? Pues la proclama fundamental del feminismo se asienta en un clamor de justicia. Pensemos, por ejemplo, en las marchas recientes

Feminismo/s 34, diciembre 2019, pp. 317-338 
bajo la consigna «ni una menos». ¿Puede ser en verdad desproporcionada una manifestación de este tipo? Muchos criticaron, por encontrarlo escandaloso, ciertas expresiones artísticas subidas de tono, donde algunas manifestantes exhibieron partes de su cuerpo. ¿Se puede criticar, de forma razonable, tal cosa? Al parecer no, a menos que se vulneren, claro está, derechos de terceras personas. Fundamentalmente porque se demuestra una incomprensión y una falta de empatía absolutas: aquello por lo cual se estaba protestando era la violencia machista, que mata y vulnera a cientos de miles de mujeres.

La desproporcionalidad, entonces, parece ser más bien de quienes se escandalizan de las manifestaciones feministas, ya que no se indignan en igual proporción frente al daño de que son víctimas tantas mujeres. Adicionalmente, la demanda de justicia por parte del movimiento feminista no puede ser, al menos en esencia, desproporcionada, precisamente porque demanda lo contrario: la reparación y la abolición de la injusticia, esto es, la restitución del equilibrio y la proporción.

\section{7. «El feminismo se propone destruir a los hombres»}

Otra de las falacias que circula recurrentemente en medios de comunicación y redes sociales está asociada con la imputación de «desmesura» al movimiento feminista: el señalamiento que lo acusa de buscar venganza en contra de los hombres. Aquí se esconden dos creencias erróneas que vuelven a este argumento completamente inverosímil. La primera consiste en confundir venganza con justicia. Sin duda, es posible establecer relaciones entre ambos conceptos $^{19}$; no obstante, existe una diferencia fundamental: la venganza solo mira hacia el pasado -busca la reparación de un hecho ya sucedido-, mientras que la justicia no solamente mira hacia el pasado, sino esencialmente también hacia el futuro, es decir, no se busca en exclusiva la reparación de una iniquidad acontecida, sino que este hecho no vuelva a repetirse, es decir, que no le suceda a otras personas. Desde el punto de vista de la motivación, podría decirse que la venganza es unilateral y egoísta -busca la reparación de

19. Por ejemplo, Robert Solomon (21) señala que desde el punto de vista de las emociones asociadas a dichos conceptos, existe un conjunto que es común a ambos: la ira y la indignación frente al acto injusto, el alivio y la exaltación tras la reparación de la injusticia.

Feminismo/s 34, diciembre 2019, pp. 317-338 
un caso particular-, mientras que la justicia es altruista y de mucho mayor alcance -busca la reparación del caso particular, pero apuntando también a su no reiteración, a que no existan otras víctimas que vuelvan a sufrir lo mismo-. Esta clarificación de los conceptos de venganza y justicia permite ver hasta qué punto la acusación según la cual el feminismo busca venganza en vez de justicia es infundada.

En segundo lugar, la incriminación de que el feminismo busca venganza contra los hombres es igualmente desacertada. La lucha del feminismo es contra el androcentrismo y las estructuras patriarcales ${ }^{20}$-por la inequidad que generan-, no contra hombres de carne y hueso. Lo que se busca erradicar, por tanto, son formas de pensar, de actuar y de hablar, maneras de estructurar y organizar las relaciones humanas, estructuras de poder, roles y funciones sociales. Estas formas de pensar y de actuar androcéntricas, que durante decenas de siglos han permeado nuestra educación y nuestras costumbres, no sólo son encarnadas por hombres, sino también por mujeres. El objetivo del feminismo, en consecuencia, es desmontar una ideología, y no afecta a individuos concretos. Decir luego que su objetivo apunta a castigar a los hombres, no parece ser más que una maniobra argumental mal intencionada, que se propone desviar el foco de atención.

\section{CONCLUSIÓN}

Hasta aquí se han analizado diferentes argumentos falaces con los que suele atacarse al feminismo, sin la pretensión, claro está, de haber agotado la complejidad de la temática. Por otra parte, sería un error interpretar la perspectiva de análisis ofrecida como una tentativa consistente en blindar al feminismo frente a toda posibilidad de crítica. Los objetivos han sido, más bien, despejar el terreno de discusión para hacerla mayormente fructífera, por un lado, y volver evidente en qué consiste el sentido que el movimiento feminista continúa revistiendo, por el otro. En este trabajo se ha defendido la existencia de una conexión intrínseca entre los conceptos de feminismo y justicia; por eso cabe concluir que quienes se empeñan en desacreditarlo, avalan implícitamente con su actitud innumerables injusticias que se siguen cometiendo en

20. Que, por cierto, no solamente perjudica a mujeres, sino a innumerables hombres también. 
contra de mujeres pertenecientes a todas las latitudes. Es preciso insistir en este punto, porque si bien el activismo ha conseguido valiosísimas conquistas, la tarea no está concluida. El feminismo importa precisamente porque la misión de visibilizar, reparar y eliminar las tropelías de las que han sido y continúan siendo objeto mujeres de todo tiempo y lugar, no han cesado. Su valor, por lo tanto, sigue siendo actual y no simplemente histórico.

\section{REFERENCIAS BIBLIOGRÁFICAS}

Aristóteles. Política. Madrid: Gredos, 1988. (Traducción de Manuela García Valdés)

Butler, Judith. El género en disputa. El feminismo y la subversión de la identidad. Barcelona: Paidós, 2007.

Comesaña, Juan. Lógica informal, falacias y argumentos filosóficos. Buenos Aires: Eudeba, 2001.

Copi, Irving, y Carl Cohen. Introducción a la lógica. México: Limusa, 2007.

Costa, M. Victoria. «The Indeterminacy of Rawls's Principles of Justice for Women's Freedom from Domination». John Rawls: Debating the Major Questions. Eds. Sarah Roberts-Cady and Jon Mandle. Oxford: Oxford University Press. En prensa.

Deigh, John. «Empathy, Justice and Jurisprudence». The Southern Journal of Philosophy 49 (2011): 73-90.

Franulic Depix, Andrea. «Por un análisis feminista del discurso desde la diferencia sexual». Revista ALED 15. 1 (2015): 7-22.

Maffía, Diana. «Epistemología feminista: La subversión semiótica de las mujeres en la ciencia». Revista venezolana de estudios de la mujer 12. 28 (2007): 63-98.

Maffia, Diana, y Mauro Cabral. «Los sexos ¿son o se hacen?». Sexualidades migrantes. Género y transgénero. Comp. Diana Maffía. Buenos Aires: Feminaria, 2003. 86-96.

Moller Oskin, Susan. Justice, Gender, and the Family. New York: Basic Books Publishers, 1989.

Moore, George Edward. Principia Ethica. Cambridge: Cambridge University Press, 1903.

Nelson, Mark. «Is/Ought Fallacy». Bad Arguments. 100 of the most important fallacies in Western Philosophy. Eds. Robert Arp, Steven Barbone, Michael Bruce. Oxford: Wiley Blackwell, 2019. 360-363. 
Nussbaum, Martha. Women and Human Development. The Capabilities Approach. Cambridge: Cambridge University Press, 2000.

Nussbaum, Martha. Frontiers of Justice. Cambridge: Harvard University Press, 2006.

Oseguera Gamba, Jorge. La falacia naturalista. Diss. Universidad Nacional Autónoma de México, 2012.

Pujal, Margot. El feminismo. Barcelona: Editorial UOC, 2015.

Rachels, James. Introducción a la Filosofía Moral. México: FCE, 2007.

Roberts, Robert. «Justice as an emotion disposition». On emotions. Ed. John Deigh. Oxford: Oxford University Press, 2013. 14-28.

Salles, Arleen. «Percepción y Emociones en la Moralidad». Isegoría. Revista de Filosofía Moral y Política 20 (1999): 217-226.

Schopenhauer, Arthur. «Sobre el fundamento de la moral». Los dos problemas fundamentales de la Ética. Madrid: Siglo XXI, 2002. (Traducción de Pilar López de Santamaría).

Shklar, Judith. The faces of injustice. New Haven: Yale University Press, 1990.

Solomon, Robert. «Sympathy and Vengeance: The Role of Feelings in Justice». In Defense of Sentimentality (The Passionate Life). Ed. Robert Solomon. Oxford: Oxford University Press, 2004. 20-42.

Scalambrino, Frank. «Reductio ad Hitlerum». Bad Arguments. 100 of the most important fallacies in Western Philosophy. Eds. Robert Arp, Steven Barbone, Michael Bruce. Oxford: Wiley Blackwell, 2019. 212-214.

Violi, Patrizia. El infinito singular. Madrid: Cátedra, 1991.

Wrisley, George. «Appeal to emotion: force or fear». Bad Arguments. 100 of the most important fallacies in Western Philosophy. Eds. Robert Arp, Steven Barbone, Michael Bruce. Oxford: Wiley Blackwell, 2019. 98-101. 